\title{
UNA MIRADA TEOLÓGICA AL MUNDO DE LA UNIVERSIDAD EN SU TAREA DE BÚSQUEDA DE LA VERDAD
}

Xavier Villar O.

"Entonces Pilato le dijo: "¿Luego tú eres Rey?" Respondió Jesus: "Si, como dices, soy Rey. Yo para esto he nacido y para esto he venido al mundo: para dar testimonio de la verdad. Todo ol que es de la verdad. escucha mi voz." Le dice Pilato: "¿Que es la verdad?"

Este texto del evangelio de Juan me resulta muy interesante como recurso para expresar una reflexión sobre el mundo de la universidad a partir de un semestre el primero del 2001, en el cual, tanto la vida cotidiana con sus problemas y procesos propios. como el acontecimiento del conflicto estudiantil de mayo, nos desafian a preguntarnos sobre la realidad en la que estamos inmersos y sobre la finalidad de la tarea de la Universidad de construir verdad tanto en el conocimiento como en la formación de personas adultas que se van integrando en la sociedad chilena.

La pregunta de Pilatos "¿qué es la verdad?" finaliza un diálogo que hace el evangelio además de con la cultura judia con la totalidad del mundo conocido: el Imperio Romano y su cultura helenista que por tradición filosófica y acontecimientos históricos se pregunta por la posibilidad de conocer y fundamentar la realidad en la Verdad; esta era una pregunta epistemológica. racional. En cambio la cultura judia tenia muy claro ese fundamento de la verdad: Dios mismo. En la cultura judia la cuestion no era tanto el saber qué es la verdad sino dónde se encontraba esa verdad de Dios. Obviamente estaba en el templo y el cumplimiento de las tradiciones encarnadas en la Torah o Ley. Para ambos mundos, el judio y el grecorromano Juan plantea que la única verdad posible, aquella que va a colmar las expectativas del ser humano. aquella que le va a dar la vida eterna es re-conocer a Jesús de Nazareth como el Mesias, el Logos o palabra de Dios hecha persona. Indica Juan por tanto. por que es necesario preguntarse y responder por la verdad: porque la pregunta por la verdad alude a la posibilidad de dar sentido a la existencia, a la historia tanto personal como social y a la posibilidad de encontrar los caminos de la 
felicidad humana, aquellos que están presentes como interrogante tanto en los filósofos griegos como en los eruditos judios y por sobre todo en el pueblo sufriente y pobre. mayoria de ambos mundos.

Nolan y Crossan, teólogos contemporáneos', nos ubican en un contexto sociohistórico de expectativas apocalipticas en el mundo judio. es decir, la creencia en que el Mesias y el juicio de Dios al mundo estaban muy cerca. Expectativas que pasarán a las primeras comunidades cristianas y que se reflejaran en los evangelios (Lc 12.35ss: Mc 13,33: Lc 18.20-36: Mt $25,31-46$; etc). Por otra parte en el mundo grecorromano el imperio romano estaba en la cúspide de su poder pero por ello mismo ya con grandes signos de decadencia y de violencia que provocaban escepticismo, decepción y cuestionamientos religiosos y sociales a la población en general.

Juan nos muestra como la Verdad de Jesús genera escándalo en la sociedad judia: Jesus es ejecutado como blasfemo y agitador o es considerado algo absurdo e incluso aberrante y peligroso para el saber griego y romano. El mismo poder romano se sentirá amenazado politicamente por el cristianismo y creerá tener que defenderse de él violentamente.

"¿Que es la verdad?" No es desde esta perspectiva una pregunta inocente y especulativa sino que afecta a lo más esencial y necesario del ser humano y de la sociedad. El mismo evangelio nos muestra como tras formular Pilato la pregunta todo se acelera hasta culminar en la crucifixión y resurrección de Jesús.

\section{A. Sociedad, Universidad Y Globalización.}

Hoy podemos analizar nuestra sociedad a través precisamente de la misma pregunta de Pilato:

"la caida del Muro de Berlin indica el fin de una politica ontendida como promesa de liberación. el fin de la vision teológica de la politica; nos hallamos ante ol fin del mesianismo politico y religioso"..(Neoliberalismo y religion. Verbo Divino. Estella. 1998. p.45)... el caso es que la atmósfera utopica y mesiánica en que todos aquellos intentos militimtes y esperanzados se desarrollaron. ha desaparecido en muchos sectores y en la sociedad como conjunto cultural. Ya no es posible para muchos, pensar el mundo on coordenadas de transformación historica y de liberación. La concicncia de fracaso de los intentos revolucionarios realizados en los iltimos liempos. ha calado profundamente en el subconsciente

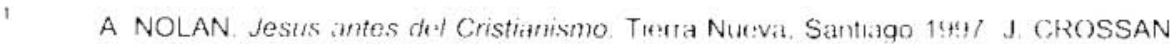

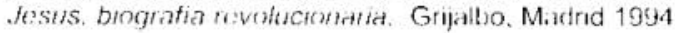


colectivo de la sociedad. Se ha perdido la "inocencia idealista" y la sociedad ha quedado vacunada contra todo planteamiento utópico-mesiánico; el ciudadano moderno actual neoliberal se "ruboriza" ante la sola presencia de una utopia mesiánicoescatológica, o se sonrie benévolamente. Se ha hecho escéptico, pragmático. incrédulo ante las utopias, vuelto hacia el aqui y el ahora sin concesión alguna para devaneos mesiánicos'í.

Tal y como confirma Vigil, las respuestas que da la sociedad ante la pregunta sobre qué es la verdad son una negación de grandes verdades que sustenten la realidad. Desde la decepción o el cinismo estas respuestas contienen una dimensión ética que se puede afrontar o se puede eludir ya que la cuestión final en juego es si es posible transformar esta realidad o simplemente vivimos en el mejor mundo de los posibles.

Observamos que los rasgos que fundamentan a nuestra sociedad actual son el excepticismo, pragmatismo (utilitarismo), hedonismo, religiosidades esotéricas e individualistas dentro de un sistema economicista en el que prima el tener sobre el ser y deja multitud de victimas anónimas (dentro y fuera de nuestra sociedad) en función del único dogma verdadero: el mercado y sus leyes inmutables y cuasidivinas, etc. Que haya este tipo de respuestas no quiere decir que ya no existe la verdad en la sociedad ni que la sociedad sea intrinsecamente mala o perversa, sino que la cuestión sobre la verdad ha adquirido otros rasgos que habrá que saber buscar para seguir ofreciendo el proyecto de Jesús de Nazareth como verdad que sustente la existencia de las personas y sociedades.

\section{La Universidad construye conocimiento.}

La construcción del conocimiento por parte de la universidad presupone una objetividad que sustenta ese conocimiento. Afirmar esto ya es una posible solución a la encrucijada sobre el encuentro con la Verdad. Es posible y necesario la objetividad en los conocimientos técnicos pero hay que añadir que esta objetividad está necesariamente filtrada por la subjetividad tanto de quien los transmite como de quien los recibe. De hecho hoy ya no hablamos pedagógicamente de transmitir contenidos sino de construir el conocimiento en la interacción profesor-alumno. Una verdad sostenida por la persona que conoce es una comprensión mejor del actual camino de respuestas sobre la verdad. No será ya por tanto una Verdad que se impone por su objetividad al sujeto sino una verdad que se hace posiblemente objetiva en cuanto es conocida por una persona o personas. Decir esto no es caer en un relativismo epistemológico sino volver a aquello que ya desde Juan indicaba: la absoluta relación entre verdad y sentido,

2 Cfr J.M.VIGIL. "Desafios Actuales a la Espiritualidad de la Liberación", en: RELAT 268 , p. 2. 
verdad y felicidad, verdad y existencia. Asi si es posible entender el auténtico significado de servir a la verdad como servir al individuo, a la sociedad en la búsqueda de su sentido, de su felicidad. en la proteccion y defensa de su existencia. Juan nos muestra a la verdad es decir Jesús de Nazareth lavando los pies a sus discipulos y hermanos pidiendoles que si están con El, (con la verdad) hagan lo mismo (Jn 13,1-15).

La Universidad es un eco o reflejo de la sociedad en la que vivimos. por lo que Jose Maria Vigil se atreve a afirmar de ella:

en la America Latima do los 90. y mirandola desde hego desde los intereses de los pobres, podomos descubrir que entramos hace tiempo en una "noche oscura" que. psicologicamente, puede ser explicada dentro de las hipotesis de la psicologia conductista como depresión. Nuestra sociedad latinoamericana. como resultado de la crisis del paso de los 80 a lus 90 -que cuiminó una trabajada historia de varias décadas de lucha y conflicto. de heroismo y martirio de esperanzas y fracasos-. entró en una etapa de depresion psicológica en muchos sectores populares que hasta entonces habian llevado el peso de la militancia y de la esperanza. Todos los sintomas colectivos evocan el mismo sindrome de la depresion individual, con un claro paralelismo."

$Y$ hay que afirmario con letras mayúsculas, esta sociedad con su sistema salvajemente neoliberal da muchas razones para que sus miembros más débiles, la mayoria, sufran objetivamente situaciones de injusticia y avasallamiento tanto material como espiritual con las consecuencias de rasgos sociales depresivos."

Otra opinión muy parecida es la del teólogo González Faus que afirma que las continuas crisis económicas unidas a una impresión de crisis cultural son sintomas de enfermedad de la ideologia predominante. la del mercado que impregna y determina todos los aspectos de la realidad. $Y$ en concreto define esta enfermedad como de las cuatro "d":

el mercado ya no detecta las necesidades de la sociedad

el mercado no distribuye bien

el mercado despilfarra

el mercado degrada ${ }^{5}$

Muchos sintomas están presentes en los jóvenes. Incluso más allá, porque la depresión es algo muy subjetivo, de que nosotros como adultos

3 Cfr Idem, p. 4

4 Cuando los iddultus nos asombramos e indignamos ante la pasividad que muchas veces tienen los jovenes no nos damos cuenta de que en el fondo no deja de ser un tipo de resistencia propia de grupos con poca capacidad de respuesta colectiva positiva y es tipica de los sectores más débiles socialmente (cfr J. CROSSAN. Op cit). Cfr JiGONZALEZ FAUS, Las Cuatro Deficiencias del Mercado, reflexion cultural sobre la crisis económica". en: RELAT 132. pp.2-5 
nos asombremos y hasta nos mostremos escépticos con las razones, análisis y reacciones violentas que manifiestan los estudiantes. Puede parecer un tanto arriesgado o paternalista afirmar que los jóvenes universitarios, los cuales son privilegiados ya por haber accedido a estudios superiores, sean uno de los grupos débiles de la sociedad pero como he analizado hasta ahora muchos datos me inducen a creer que es cierto.

\section{La Universidad busca servir a la sociedad.}

Cuando hablamos de Universidad podria haber una cierta tendencia natural por reflejo de la ideologia de la sociedad en la que vivimos a concebir su eficacia en cuanto se la comprende como una empresa que debe dar sus servicios de forma eficaz a sus clientes. Es decir. su identidad queda impregnada de una orientación mercantilista. Por el contrario una mirada a la historia de la génesis de la universidad (s. XII aprox.) nos dice que el sentido de ella es por esencia servir a la sociedad ofreciendo un espacio donde compartir los saberes de todos el mundo conocido y sostener el buen funcionamiento de la sociedad. Para confirmar esto no hay nada mejor que dar cuenta de la "malla curricular" de los tiempos de la edad media cuando nacieron las universidades:

Derecho: para el ordenamiento juridico de la sociedad

Medicina: para la sanación de sus individuos

Teologia: para la orientación moral y espiritual

Artes del lenguaje y de la buena construcción del pensamiento: lógica, dialéctica, etc.

Aún con los cambios de perspectivas de identidad de lo que es una universidad, históricamente ella ha sido un espacio donde se han vivido como esenciales los valores de la libertad, del servicio a la sociedad y de búsqueda de la verdad, incluso muchas veces oponiéndose a lo que se consideraba correcto en su contexto social e histórico. Esto es dado por la peculiar configuración de la comunidad universitaria donde el grupo fundamental son los jóvenes estudiantes y que, como dice la Centesimus Annus, la búsqueda de la verdad que se renueva cada generación caracteriza la cultura(alma) de la nación y este patrimonio de valores heredados y adquiridos es siempre objeto de contestación por parte de los jóvenes. Contestar es según la enciclica: "no necesariamente destruir o rechazar a priori sino someter a prueba en la propia vida y, tras esta verificación existencial. hacer que esos valores sean más vivos, actuales y personales discerniendo to que en la tradición es válido respecto de falsedades y errores o de forma obsoletas. que pueden ser sustituidas por otras más en consonancia con los tiempos" (CA 50). Es muy interesante ver dónde Juan Pablo II pone el énfasis de esta labor: "esta (sic) se realiza en el corazón del hombre. y el modo como éste se compromete a construir el 
propio futuro depende de la concepcion que tiene de si mismo y do su destino...".

Estos dos rasyos o caracteristicas de la identidad universitaria: servicio a la sociedad y espacio de formación de jóvenes contestadores "per se" de la cultura. nos remiten a su identidad ética. tal y como afirma Annette Kleinfeld (paradojicamente refiriéndose a la empresa como otro subsistema social similar en cuanto tal a la universidad) al sostener que los valores son el punto de partida para el ulterior desarrollo o para la atinada configuracion de la cultura y de la identidad de un subsistema social'

La pregunta que surge es ¿que tipo de servicio o como servir a la sociedad? Pienso que el principal modo de servir a la sociedad es acentuar frente a otras realidades el servicio a los jóvenes aún más de lo que se está haciendo. Desde la experiencia del semestre pasado mo surgen varias razones que fundamentan tal afirmacion:

- Porque una cosa tan obvia puede olvidarse cuando se habla de búsqueda de la verdad o construir saber especifico y no se ve integrado o insertado en el objetivo fundamental y prioritario de formar a los jóvenes como ciudadanos profesionales

- Porque es fundamental para la identidad de la Universidad que los distintos grupos o estamentos que la conforman vivan y se identifiquen plenamente con la institución y con su misión. $Y$ hoy pienso que es más un interrogante que una constatacion.

- Porque los jóvenes no se identifican con la institución y es más. cuestionan su coherencia ética respecto a la real práctica de un espiritu evangèlico propio de la identidad católica de la universıdad en la relación y servicio a ellos.

- La impresión de que no hay una integración o unión entre estamentos universitarios que conforme una autentica comunidad universitaria que sirva para un mejor servicio a los jóvenes.

Da la impresión que la realidad de los jovenes universitarios, aunque no lo reflejen los datos pero sí los diálogos y la relación con ellos. es de una gran precariedad, tanto económica de ellos y de sus familias como afectiva, y no sienten que la institución y la dinámica universitaria les ayude a resolverla sino que incluso ai contrario. Muchos se sienten avasallados por la estructura universitaria y sienten deficiente la relacion de las personas que integran la institución hacia ellos. A ello habria que anadir la poca relación entre estudiantes y académicos también constatada en el último conflicto

A. KLEINFELD, Identudad Empresariak mediante la Orentiacion Etıca", en: Concifum (2000) $214-228$ 
estudiantil y, ¿por qué no?, la poca relación solidaria y profunda entre ellos mismos que se reduce a ámbitos muy pequeños de amistad y/o "pololeo"

"La juventud no es un tiempo. mi una generación. ni una categoria homogénea a la que uno pueda examinar, desde fuera. con objetividad. sin emociones ni prejuicios. La juventud es un cometa de riesgos y de oportunidades. de amenazas y de promesas, una intromisión en el sistema cósmico de los adultos. Y como a los cometas. hay que entenderla. más que un conjunto sólido, como un torbellino, abigarrado y turbulento. reflejo de las diferentes coyunturas de oportunidad que nuestra sociedad ofrece a los recién llegados " ".

\section{El fenómeno de la Globalización}

La ideologia capitalista que sustenta este fenómeno de interrelación y comunicación planetaria provoca que la suma de egoismos personales y determinaciones economicistas colectivas genere una dinámica social que se hace intrinsecamente perversa en sus cristalizaciones juridicas, culturales y económicas. Evidentemente me refiero a la sociedad de corte neoliberal y globalizada que está siendo configurada desde hace años.

Hablar de Globalización sin querer caer en un maniqueismo típico de la confrontación de lo viejo con to nuevo es aceptar primeramente que el fenómeno es hoy innegable y que tiene perversidades pero también posibilidades de humanización. El problema es que la ideologia que hoy sostiene en la práctica la globalización es económica y de corte neoliberal, curiosamente el nuevo rostro de aquel capitalismo del siglo XVIII de Smith que abogaba porque el egoismo personal crearia riqueza social.

Para Leonardo Boff no sólo es un asunto de nueva cara de un capitalismo antiguo sino que la globalización es sostenida y potenciada por los mismos intereses y mecanismos que surgieron desde la colonización de América por Europa. La violencia efectiva y social. la imposición, el colonialismo imperial y el ansia de lucro personal que tantas tragedias trajeron al hoy denominado tercer mundo parecen ser para él los que simplemente persisten con el nuevo rostro de la globalización" ${ }^{11}$.

La ideologia mercantilista es aquella que nos dice que si dejamos libre al mercado en su dinamismo interno ayudado por las nuevas tecnologias de la comunicación y de la información, las cuales son las que han generado la

H

En este analısis coincidimos un grupo de académicos cristıanos que nos dedicamos, a raiz del conflicto estudiantil del primer semestre de este año, a reflexionar sobre la realidad universitaria y con la participación puntual de estudiantes para que nos aporten su visión propia J.I. RUIZ OLABUENAGA. "La juventud liberta", en VVAA: Nuevas pautas de ocio de tos jóvenes. Diputación Foral de Gipuzkoa, 1999.

L.BOFF, "La Globalızación vista por un Teólogo" en Ei murico. 2 de agosto de 1999 
globalización, éste traerá a la larga progreso y desarrollo para todos. Las inconveniencias, o los efectos negativos "colaterales", sólo es cuestión de tiempo para que desaparezcan. El problema es, para el economista y teólogo Josep Maria i Serrano, cuáles son estos efectos negativos "colaterales":

- El acceso desigual a las tecnologias de la información y la comunicación dependiendo del grado de desarrollo de los paises.

- El aumento de la pobreza. En Julio de 1999, el Secretario General de la ONU, Kofi Annan anunciaba en Ginebra que el número de pobres en el mundo se habia duplicado desde 1974. Y asi, de los 6.000 millones de habitantes del mundo de 1999, la mitad tenian que sobrevivir con tres dólares al dia; y uno de cada dos de estos pobres no ganaba más de un dólar diario.

- Una cronificación de la cesantia, aumento de la precariedad laboral y social en los paises industrializados y también un incremento de la desigualdad de ingresos.

- Un desplazamiento del poder económico hacia los "nuevos ricos"; la desconexión de los mercados financieros respecto a la economía real; la tendencia a la concentración empresarial; una acentuación de la competencia y el alejamiento y la progresiva anonimización del capital.

- Deterioro del medio ambiente.

- Una pérdida de margen de maniobra de los Estados a la hora de establecer politicas económicas que favorezcan a todos los ciudadanos. Y el FMI y el Banco Mundial, al intentar poner orden en determinadas economias subdesarrolladas, han acentuado su pobreza y su dependencia del exterior.

- Una cultura del consumismo global que provoca cambios de valores e incluso comportamientos adictivos.

- Una homogeneización de visiones de la realidad, de valores, etc., a través de los medios de comunicación provenientes del primer mundo. ${ }^{11}$

En sintesis, el autor habla de globalización y no de mundialización porque no todo el mundo se ha visto favorecido por este proceso. $Y$. en cambio, la globalización ha conectado zonas geográficamente distantes del planeta. Asi mismo "la globalización ha creado una división entre los que la comprenden y la aprovechan y los que la sufren. Estos últimos son atraidos por los agujeros negros del capitalismo informacional, en cuyo seno es

11 JMARIA Y SERRANO, "La Globalización", en: Cuadomos Cristianismo y Justicia $(2001) 2-5$. 
imposible estadisticamente escapar al dolor o a la degradación progresiva de la condición humana"t?

Esta situación mundial que nos afecta nacional y localmente determina nuestra capacidad de ver y descubrir la verdad sobre el ser humano y la sociedad ${ }^{13}$. Quizás lo más preocupante que he observado entre los estudiantes es que la mayoria son bastante inconscientes de los aspectos e ideologias que existen tras este fenómc no de la globalización ${ }^{14}$. La Universidad por una parte está funcionando, en mi opinión, como el resto de la sociedad, es decir, está alentando la conciencia de que la globalización es buena y hay que sumarse al carro tecnológico tanto material como didácticamente. Esto no es malo ya que como afirmé anteriormente la globalización tiene posibilidades de progreso y de crecimiento humano y social.

Sin embargo ¿hasta qué punto mostramos (los académicos, las actividades de extensión, etc.) ese otro aspecto negativo y objetivamente mucho más impactante que el lado positivo de la globalización? ¿Cómo revelamos la Verdad sobre nuestro mundo, nuestra sociedad? Mostrarrevelar significa a mi entender un proceso activo de interacción instituciónprofesor-alumno en la búsqueda de la verdad a través de toda la dimensión formativa ética como tarea de la universidad tanto sistemática como transversalmente. $Y$ es esta afirmación la que da paso al siguiente punto de mi artículo.

\section{B. La ceguera para descubrir la Verdad}

El evangelio de Juan con el diálogo de Jesús y Pilato muestra el final del drama que cruza todo el evangelio: la incapacidad de reconocer la verdad por el mundo. Los judios con su sabiduria sobre Dios, y los griegos y romanos con su saber filosófico y político, están ciegos. Terminan matando la verdad, al Mesias, a Aquel que quienes lo reconocen son hechos por él Hijos de Dios (Jn 1,12). Uno se pregunta qué es lo que a unos y otros, aún actuando de buena fe, en general les impide ver bien. No sólo respecto al tema evangélico, aunque ciertamente es para nosotros los cristianos el tema fundamental de la existencia: el ser humano se encuentra con su verdad más profunda en cuanto reconoce a Jesús como Señor. Me refiero a qué

Es la opinión de R.M. SOLOW. Premio Nobel de Economia, al expresar: "jAh, si, la giobalización! Es una maravillosa excusa para muchas cosas".

14 Todos los alumnos de un curso de ética profesional que dicté este semestre pasado afirmaron al final del tema sobre la globalización que creian hasta entonces que globalización era progreso tecnológico y económico sin saber su cara oscura o ideológica. El nuevo análisis que les ofreci y reflexionaron juntos les dio, en palabras de ellos, una nueva conciencia de lo que suponía la globalización y de las consecuencias éticas derivadas de ella.
} 
capacidad de analizar, de ver hoy en dia tenemos para poder actuar en consecuencia. Estoy seguro que mucho de lo que determino la incapacidad de judios, griegos y romanos para descubrir la verdad nos determina hoy en dia: los intereses personales y las estructuras e intoreses sociales

En concreto desde el mismo evangelio se nos dirá que la tragedia humana es la incapacidad de vivir la vida en cuanto entrega y solidaridad hacia los demas. Y sın embargo el evangelio nos dice que esa es la posibilidad de perfeccion o de plenitud (cfr Jn 13.1ss; Mt 5.48: Lc: 6.36). En cambio nuestras inseguridades. miedos y anhelos muchas veces nos instan a actuar en el inmediato beneficio propio aun a costa (muchas veces sin quererlo realmente) del bien de los demás. Es el egoismo puro y duro.

\section{El diálogo entre Jesús y Pilato es un diálogo entre el poder $y$ sus victimas}

El contexto del diálogo entre Jesús y Pilato es el juicio a Jesús del poder religioso y politico como blasfemo y agitador político. El diàlogo sobre la verdad está por ello interrogado. determinado por ese marco ético. Esta situación que Juan nos plantea clarifica esa intima relación entre lo noético y lo ético, verdad y ética. Pero esta fundamentación es a su vez una propuesta de interpretación de toda la vida de Jesús como lá consecuencia de una opción de ubicación vital (ética) desde la que descubrir y ponsar la realidad (noética). Esta ubicación vital es propuesta en el t:vangelio como identificación y encuentro. de Jesus y de quienes quieren seguirle. con los pobres y pecadores a través de la comensalia abierta y de lá sanación.

Es importante mostrar las razones por las que Jesus se identifico con los pobres, se hizo uno de elios. El himno cristológico de Fil 2, 6-11 en una perspectiva teológica nos muestra cómo la identificación era propia del plan de Dios para mostrar su amor a la humanidad. Cristo Jesus se despojo. se encarnó y se hizo obediente hasta la nuerte. y muerte en cruz. Una concepción ya superada es concebir como humillacion el hacerse Hombre. como si lo humano fuese algo indigno. Esta concepción bebe de la filosofia griega platónica que concibe lo material, el mundo, como una simple sombra imperfecta de lo divino. Pero una mirada más profunda al cvangelio nos dice que la humillación no es hacerse Hombre sino el mas pequerio o indigno de los hombres: una más de tantas victimas, hasta el extremo de terminar su vida en la cruz, una de las más ignominiosas y terribles maneras de morir de ese tiempo. Por lo tanto Pablo nos muestra que la identificación con los más pobres es en Jesús propio de su ser divino.

Pero aún tenemos que explicar desde la dimensión histórica y humana de Jesús " qué es lo que le movió a identificarse con las victimas de su tiempo. Vaie la pena expresarlo en palabras de Albert Nolan:

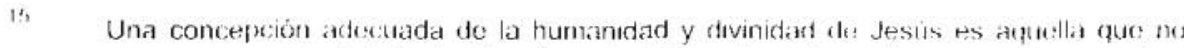

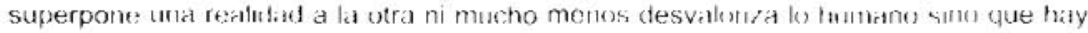


La respuesta aparece con toda evidencia a lo largo y ancho de los evangelios: sentia compasión.

"le dio compasión de la gente y se puso a curar a los enfermos" (Mt14.14). "Sintió compasión porque andaban maltrechos y derrengados como ovejas sin pastor"(Mt 9.36). Compasión sintió igualmente por la situación y las lágrimas de la viuda de Nain(LC 7.13). Expresamente se nos dice que sintió compasión por un leproso (Mc 1.41), por dos ciegos (Mt 20,34) y por quienes no tenian nada que comer (Mc 8.12. par).

A lo largo de los evangelios, aun cuando no se emplee la palabra, podemos sentir este movimiento de compasion. Una y otra vez dice Josús a la gonte: "no lloren". "no se inquieten", "no tengan miedo". No le conmovia la grandeza del enorme templo (Mc13.1-2) sino la pobre viuda que echo unas monedas en el cepillo del Templo (Mc12.41-44). Mientras todo el mundo se quedó pasmado ante el milagro de la hija de Jairo, él se preocupo porque le dieran a la niña algo de comer (Mc 5.4243).

Lo que de diferente realizo el buen samaritano de la parábola fue la compasión que sintio por el hombre que sc hallaba medio muerto a la vera del camino (Lc 10,33). Lo que de diferente realizó el padre amoroso de la parábola fue el exceso de compasión que sintió por su hijo pródigo (Lc 15.20). Lo que de diferente hizo Jesus fue sentir una ilimitada compasion por los pobres y oprimidos.

El término "compasion", sin embargo. es todavia demasiado inexpresivo para reflejar la emocion quo movia a Jesús. El verbo griego "esplagjinizomai". usado en todos ostos textos. se deriva del sustantivo "esplagjnon". que significa vientre, intestinos. entrañas. corazón. es decir. las partes internas de donde parecen surgir las emocionos profundas. El verbo griego. por consiguiente, indica un movimiento o impulso que fluye de las propias entrañas. una reaccion visceral. Por eso los traductores han recurrido a expresiones como "se sintio movido de compasión o lástima". "sintio pena" o "su corazón se derramo hacia ellos". Pero ni siquiera estas expresiones captan las profundas connotaciones fisicas y emotivas de la expresion griega para referirse a esa compasión. ${ }^{\text {th }}$

que entender ambas reatidades (n Jesis cono plenas cada una en si misma. Por tanto sólo cabe concebirlas la una como sacramento de la otra En palabras sencillas de LEONARDO BOFF: "in ser tan humano como Jesús suto pudo serlo Dins" 
La comensalia abierta (concepto tomado do Crossan) define uno de los gestos o conductas más caracteristicos de lit manera de relacionarse Jesus con los potures y pecadores además de con las personas "de bien" de su sociedad. Se puede definir la mesa como un modelo de sociedad en miniatura. En esos tiempos compartir la mesa era ontrar en comunión con quienes se hacia ese gesto, hacerse o reconocerse iquales unos a otros. En la sociedad judia por eso se tenia mucho cuidado con quien se compartia la mesa porque estaba en juego la dignidad social y la pureza religiosa. Un fariseo dificilmente se sentaria a la mesa con un campesino y mucho menos con un pecador. Cabe explicarse por tanto la violencia que sentirian unos y otros por verse juntos en una misma mesa alrededor de Jesús. Posiblemente, seggun Nolan, la parábola de los que se excusan al banquete seria un episodio cierto que le ocurrio a Jesús (l c: 14.124 2-24). Para los pobres y pecadores. una ve $\angle$ superada la primera resistencia. ef hecho de que Jesús compartiese con ellos la mosa les mostró que Jesús les aceptaba como amigos e iguales y con ello se sentian liberados de la vergüenza. la humillación y de su sentido de culpa. Al demostrarles Jesus que ellos le importaban como personas. les dio una sensación de dignidad y les liberó de su cautividad. El contacto fisico que debió tener cun ellos al reclinarse a la mesa (cfr Jn 13.25) y que, evidentemente. èl nunca desaprobó (Lc, 7,38-39 ), debió de hacerles sentirse limpins y aceptables.

Además. dado que Jesús era considerado como un hombre de Dios y un profeta, ellos interpretarian su gesto de anistad como si se tratara de una aprobacion de Dios con respecto a ellos. Ahora ya eran aceptables a Dios. Su maldad, su ignorancia y su impureza habian sido perdonadas y ya no podian ser esgrimicias contra ellos".

\section{Jesús de Nazareth anuncio el Reino de Dios como núcleo de su predicación y de su acción}

El Reino de Dios para Jesús tunia un caracter social y politico en cuanto suponia ta liberacion real y concreta del ser humano de sus opresores. Para ello no hay màs que fijarse en algunos textos evangélicos basados todos en las profecias de Isiaias Cito sóto el más significativo, Lc 4.14-21:

Jesis volvio a Galilea por la fuerza del Espiritu. y sil fama so extendio por toda h region. El ina ensenimdo en sus sinagogas. alabado por todos. Vino a Nazareth. donde se habia criado y. segim su costumbio. entro on la sinagoga el dia de sábado. y se tcvanto para hacer la lectura Le entregaron el volumen del profota /saias y desenrolkando el volumm, hallo el pasaje donde estabia oscrito 
- "El Espiritu del Señor esta sobre mi porque me ha ungido para anunciar a los pobres la Buena Nueva me ha enviado a proclamar la liberacion a los cautivos y la vista a los ciegos, para dar la libertad a los oprimidos y proclamar un año de gracia del Señor.» -

Enrollando el volumen lo devolvio al ministro, y se sento. En la sinagoga todos los ojos estaban fijos en él. Comenzó. pues, a decirles: "Esta Escritura. que acaban de oir. se ha cumplido hoy."

Jesús plantea que para que el Reino se haga realidad debe partir por la conversión del corazón y tiene una dimensión totalmente espiritual en cuanto parte de una experiencia de salvación por el encuentro con Dios como Padre misericordioso, amante y compasivo. Pero es una espirituatidad encarnada, que se hace realidad en el hoy y el acá. Asi, los milagros que hizo deben entenderse como signos y realizaciones concretas de ese Reino de Dios que anuncia. Estos signos o milagros que son en su mayoria curaciones, algunos milagros sobre la naturaleza y tres resurrecciones, tienen todos ellos la caracteristica de la sanación. Sanación entendida como restauración de una creación herida por el pecado personal y social tal y como originariamente la pensó Dios. Esa restauración es corporal, social y creacional. Esa sanación es el Reino de Dios hecho realidad"s.

Para respaldar estas ideas es interesante volver a Crossan y la dimensión simbólica y politica que descubre en la propia corporalidad. Asi como la mesa era un modelo de sociedad en miniatura, Crossan afirma que el cuerpo humano es un microcosmos al que corresponderia a nivel macrocósmico la sociedad política. Dicho de otra manera: "el cuerpo es una sociedad escrita con minuisculas " $"$ ". Cita a la antropóloga Mary Douglas que sostiene que el cuerpo, como estructura compleja. puede convertirse en simbolo de otras estructuras igualmente complejas. Cabe asi considerar el cuerpo como simbolo de la sociedad y pensar que los poderes y peligros atribuidos a las estructuras sociales se reproducen a pequeria escala en el cuerpo humano y por lo tanto. añado yo, la sanación del cuerpo humano puede reproducir simbólicamente también a pequena escala la sanación de las estructuras sociales: "el cuerpo humano es algo que todos tenemos en común. Lo único que varia de un individuo a otro es la condicion social. Los

18. Hablar de sanación no sólo debe sor referido a los milaugros. Tal y como señalaba con la comensalia abierta de Jesús, os toda la vida de Jesus la que está orientada hacia la sanación. Tanto en sus milagros. como en sus palabras y en su manera de relacionarse y vivir sus discipulos. los pobres y pecadores experimentaron la sanación 0 dicho de otra manera vieron hecho realidad ol Reino que anunciaba. Es por eilo que podemos afirmar que el Reino de Dios se hace realidad on Jesús mismo y ya no será posible disociar el uno deal otro. 
simbolos que se basan en el cuerpo humano se utilizan para expresar experiencias sociales distintas ${ }^{n ? 0}$.

Podriamos extender, me parece más acertado, esta simbologia del cuerpo humano a toda la creación tal y como viene siendo la conciencia actual mundial en cuanto la intrinseca relación persona-sociedad-medio ambiente. Crossan haciéndose eco de las intuiciones filosóficas y médicas sobre la enfermedad distingue en el individuo enfermo la afección en si (el daño corporal) y el mai: experiencia subjetiva de la persona y de la sociedad sobre su afección. Pone un ejemplo:

"Pensemos por un momento en la diferencia que existe entre curar esa afección o remcdiar of mal llamado SIDA. La curación de dicha afección es, por supucsto, algo enormemente deseable. pero en ausencia de ello, siempre podemos remediar el mal que supone negándonos a marginar a los que to padecen. solidarizándonos con su dolor, y ofreciendo a sus sufrimientos nuestro respeto y cariño. "in'?

También a ello podemos añadir la importancia que se va afirmando cada vez más en la conciencia del mundo de la sanidad de que como consecuencia de ese remedio del mal la persona pueda dar sentido espiritual a su enfermedad siendo este un gran posibilitador de la sanación o paliación de la misma afección.

\section{La Verdad COMO INTERROgante Ético desde LAS VICTIMAS DEL MUNDO}

Toda esta fundamentación leológica es la que me ayuda a proponer al mundo de la universidad, que su misión como construcción del saber en la formación de los estudiantes como principal servicio a la sociedad ha de ser desde la ubicación en el mundo de los pobres o victimas de este sistema social a la manera de Jesús si quiere ser fiel al espiritu evangélico con el que define su labor. Las caracteristicas y también posibilitadores de ello serán la praxis de la sanación prioritariamente en las personas jóvenes estudiantes y en el resto de las personas que componen el mundo universitario

\section{La verdad no es objetiva: paradoja del evangelio, paradoja de Dios, paradoja universitaria}

Tomo aqui el concepto de objetividad desde un sentido peyorativo, es decir, entendida como despersonalizacion o pura especulación neutra ante

M. DOUGLAS. Natural Symbols: explorations in Cosmolngy (Citada en el libro de J. CROSSAN P.93\%.

J. CROSSAN, Op cit., p 97 
el mundo contingente como muchas veces en el inconsciente colectivo se entiende. Jesús en su opción por identificarse con el mundo de los pobres y pecadores está revelando la objetividad de la verdad de Dios en la subjetividad de su compasion y preferencia hacia ellos en detrimento de las personas de bien de la sociedad de entonces. Para ello sólo hay que fijarse en las parábolas de la oveja perdida, de la moneda perdida y del hijo pródigo del capitulo 15 del evangelio de Lucas. Hablan de un Dios que abandona (podriamos entender, si quieren, que momentáneamente) a sus hijos "buenos" para encontrar a los que se pierden. La alegria que Lucas expresa que Dios siente es totalizante, abarcante de toda la realidad. invitando a todos, a sentir la misma alegria, si queremos ser como É (Lc 15,9.31-32). Pienso que quizás no es solo una propuesta, el alegrarnos sino la condición de poder humanizarnos en cuanto reconocemos y hacemos lo mismo que Jesús.

Asi. confesar a Dios como Amor, fijandonos en cómo nos lo revela Jesús, es afirmar su total parcialidad o subjetividad en beneficio de los pobres, de las victimas, de los marginados de todo tiempo e historia.

Quizàs no exista termino más equivoco que el del amor (al referimos a Dios). En su nombre tambien se han cometido atrocidades terribles. porque. como la sabiduria popular afirma y la psicologia clinica verifica. hay amores que matan. O amores que infantilizan, o amores que se utilizan como tapadera para eludir los conflictos...

El Dios de Jesús es el Dios del amor, pero en un sentido muy determinado. que es necesario captar. comprender $y$ discriminar adecuadamente en las palabras y la conducta de Jesús: el amor que alli se nos muestra no es un amor que confunde o anula las diferencias. no es un amor indiscriminado. no se utiliza como bella escapada a los inevitables conflictos de la realidad. El amor que vemos on Jesus es un amor que discrimina: es un amor que opta en una decidida preferencia por los debiles. marginados y oprimidos: es un amor que no clude el conflicto y que, precisamente porque ama, se enfrenta, denuncia. acusa y ataca a los que son fuente de opresión, de hipocresia. de odio. de marginación etc. El amor de Dios no es sin mas la plenitud para nuestro vacio o la hábil coartada para eludir la inevitable conflictividad de la rcalidad interpersonal. social. politica. etc. La dimensión mistica despojada de la dimensión de exigencia, y de compromiso desvirtua peligrosamente la experiencia religiosa. 
La paradoja universitaria será por tanto ubicarnos en la verdad del mundo de los pobres, para buscar, encontrar y transmitir la verdad

\section{La opción por los pobres: caminos posibles de la Universidad}

Aqui es donde vuelvo a recoger los cuestionamientos y propuestas de los puntos anteriores para ofrecer caminos posibles de realizacion: me interrogaba sobre como revelamos la Verdad sobre nuestro mundo. nuestra sociedad pudiéndoie anadir ahora desde la opción, la perspectiva de los pobres. Afirmaba asi mismo que mostrar-revelar significa a mi entender un proceso activo de interacción institución-profesor-alumno en la búsqueda de la verdad a través de toda la dimension formativa ética como tarea de la Universidad, tanto sistemática como transversaimente

Proponia también la necesidad de entender a los jóvenes estudiantes como un grupo debil socialmente no tan lejano del mundo social de los pobres (aunque sea en momentos una contradicción en comparación con el resto de los jóvenes que no pueden acceder a estudios superiores). Y propongo que debemos situarnos en una praxis (es decir. estamos hablando de ética) de sanación, como Jesus, prioritariamente a estos jovenes para contribuir simbólica y realmente a la sanación social de nuestro pueblo.

\section{De un despotismo ilustrado a un camino común}

Es típica la fórmula que definió el despotismo ilustrado de fines del XVIII: Todo para el pueblo pero sin el pueblo. Podriamos traducirla aplicándola al mundo universitario como \% Universidad para los estudiantes pero sin los estudiantes". Esta es una tendencia que surge con mucha naturalidad en las universidades. Yo propongo asumir en todas las dimensiones de la Universidad \%a Universidad para los estudiantes y con los estudiantes, funciomarios y académicos. Una Comunidad Universitaria".

La dimension fundamental de concreción práctica del Reino de Dios para Jesús fue la de la fraternidad de personas sanadas, libres y solidarias. Podriamos añadir el rasgo de la ternura y de la identidad (sabian para qué estaban. quiènes eran y se apoyaban unos a otros en la alegria del compartir y en las dificultades). Hospitalidad, horizontalidad (comensalia abierta) e identidad son los rasgos que somos llamados a reproducir en la universidad.

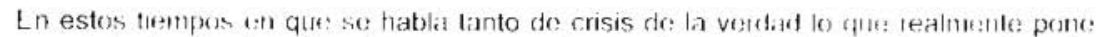
en crisis la Verediad ofleal que se nos transmule a hilves the lus medios de

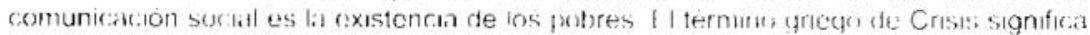
interrogación. Por tanto lo que haken los pobres as interrogar al mundo sobre la

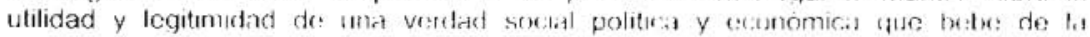

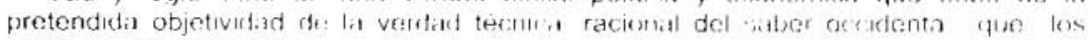
oprime. margina y mata
} 


\section{Sabernos parte en un camino y proyecto común}

La construcción del saber en la búsqueda de la verdad deberia darse en un diálogo continuo y vital entre todos los actores de la Universidad. Para ello es necesario una serie de condiciones:

- El diálogo debe estar presidido por el deseo de cada interlocutor de presentarse ante el otro tal como uno es: de presentar toda su existencia, experiencia, conocimiento.

- La búsqueda de la verdad debe ser dada a través de análisis objetivos. Es importante la sinceridad ante si mismos y crear procesos de convergencia.

- La capacidad de escuchar, de comprender desde el otro.

- El diálogo debe estar presidido por el amor al otro. Asi es posible ver en el otro a un posible hermano, y no a un enemigo que pueda causar algún daño. Aprender a dialogar es aprender a apreciar la diferencia como fuente de conocimiento, de crecimiento en el proceso de búsqueda de la verdad.

- Entrar desde el amor, que es capaz de dar confianza al otro, a fin de que éste abandone sus mecanismos de defensa y entre en el diálogo.

- Una condición indispensable es la igualdad entre los participantes en el diálogo."

Actualmente se ofrece a nivel pedagógico el concepto del profesional en formación o profesional temprano como manera de comprender al estudiante universitario y de comprenderse èl a si mismo en condiciones de igualdad a los académicos y de continuidad entre su vida presente en la Universidad y su futuro de realización laboral profesional. Deberia ser posible hacer este diálogo tanto en el aula como en otros espacios de interacción dentro de la Universidad. Exige un interés por encontrarnos unos a otros desde las actitudes anteriormente citadas. La institución deberia adecuar los espacios de la Universidad para que posibilitasen ese encuentro.

Ofrecer una formación ètica a los estudiantes a partir de la opción evangélica por los pobres que les dé los recursos propios para analizar por si mismos la realidad y dotarse de unos valores significativos en orden a su crecimiento en humanidad desde la perspectiva de la solidaridad. En una perspectiva más filosófica, Daniel Innerarity. filósofo moral vasco plantea que debemos ser memoria y proyecto de las victimas de esta sociedad desmemoriada y sin esperanzas utópicas.

2.7 J.CARRERA i CARRERA, "En busca dei Reino, una moral para el nuevo milenio" en: Cuditermos Cristianismo y Justicia (2000) 4-5. 
Hay on miestra civilizacion ima ocupacion completa con of liempo prosente. un instantaneismo huentalo de memoria y de proyecto. Este presentismo lleva a cabo la exclusion de lo que no se hace valer en la actualidad. La enemistad contra los espiritus esta alimentada por ef deseo de ahuyentar todo aquello que no encaja en la oposicion realirreal. presente/ausente. La intolorancia frente a las tradiciones culturales distintas. la falta de atencion hacia las heterogeneidades, la irresponsabilidad cconomica o ecológica hacia las generaciones venideras son aspectos de una misma ideologia de la presencia, del privilogio de los ahora absolutamente "vivos". Es prcciso dosprenderse de ese fetiche de un presente pleno y absoluto. cjercer la responsabilidad hacia los ausentes, hacia los espiritus de las victimas y los seres futuros. aquellos "no nacidos que suspiran con ojos ciegos". como lo describia el pueta Trakl.

Es decir. la formación debe estar en orden a crear una identidad que es conciencia de si pasada, presente y futura, abierta al otro sobre todo al más pobre. Asi como el joven estudiante se concibe a si mismo como un pedagogo, un ingeniero. un abogado, la universidad debe mostrarle los contenidos valóricos de esa identidad que van más aliá de lo profesional. van a su identidad integral como persona. No sólo es un asunto de cursos sistemáticos sino que deberia la Universidad crear lo que denominaria una ethosfera o atmósfera ética donde respirásemos los valores como por ósmosis, valores reflexionados. contrastados. descubiertos en actitudes y testimonios concretos de las personas, en el aula y en el campus, etc. No olvidemos que para el estudiante es muy importante la coherencia vital de sus profesores y de la Universidad.

Uno de los grandes valores que existen entre los jóvenes es el de la solidaridad y anhelo de justicia. Dentro de la Universidad existen varias iniciativas solidarias hacia otros miembros más pobres de la sociedad. Estimular esas iniciativas por parte de la institucion seria muy importante.

Asimismo, en el proceso de reflexión iniciado por un grupo de académicos cristianos del que participo. observamos la necesidad de crear espacios de solidaridad interna tanto económica como afectiva, que por un lado palien las carencias económicas y la soledad de muchos estudiantes. y por otra parte. en cuanto espacios en los que interactuásemos institución. académicos, estudiantes y funcionarios, crearian una red de relaciones horizontales en torno a la donación. a la entrega personal gratuita a otros. la cual es una de las condiciones evangélicas de humanización de nosotros mismos. El sueno es crear en todos una adhesión al proyecto de la Universidad Católica de Temuco de buscar la verdad y servir a la sociedad 
en los jóvenes con un espiritu evangélico desde unas relaciones abiertas. iguales y confiadas de unos con otros.

$$
\begin{gathered}
\text { "...pero aqui abajo abajo } \\
\text { cerca de las raices } \\
\text { es donde la memoria } \\
\text { ningún recuerdo omite } \\
\text { y hay quienes se desmueren } \\
\text { y hay quienes se desviven } \\
\text { y asi entre todos logran } \\
\text { lo que era un imposible } \\
\text { que todo el mundo sepa } \\
\text { que el sur también existe." } \\
\text { (M.Benedetti) }
\end{gathered}
$$

